\title{
Relationship between the Size and Location of the Mass and Hilar and Mediastinal Lymph Node Metastasis in Early and Locally Advanced Non-small Cell Lung Cancer
}

\author{
Mustafa Kuzucuoglu1 , Ali Gokyer2, Osman Kula33, Ali Cem Yekdes', Baran Serdar Sunal3, Yekta Altemur Karamustafaoglu5,
} Yener Yoruk 5 and Irfan Cicin ${ }^{2}$

IDepartment of Thoracic Surgery, Medical Faculty, Balikesir University, Balikesir, Turkey

2Department of Medical Oncology, Medical Faculty, Trakya University, Edirne, Turkey

${ }^{3}$ Department of Radiology, Medical Faculty, Trakya University, Edirne, Turkey

${ }^{4}$ Department of Internal Medicine, Medical Faculty, Balikesir University, Balikesir, Turkey

${ }^{5}$ Department of Thoracic Surgery, Medical Faculty, Trakya University, Edirne, Turkey

\begin{abstract}
Objective: To determine whether there is a relationship between the size and location of the mass and lymph node metastasis in non-small cell lung cancer.

Study Design: Observational study.

Place and Duration of Study: Department of Medical Oncology of Trakya University, from November 2013 to November 2018. Methodology: Records of 112 patients, who were followed up for non-small cell lung cancer, were retrospectively reviewed. Patients with distant organ metastasis (M1) and distant lymph node metastasis (N3), a previous history of malignancy, synchronous or metachronous tumors, and those for whom required data could not be obtained were excluded. Lymph nodes were evaluated according to pathology reports in patients undergoing invasive procedures. In patients without invasive procedures, lymph node larger than $1 \mathrm{~cm}$ in thorax CT, SUV above 2.5 in PET, and acceptance of metastasis at the Oncology Council was considered decisive. Diameter of the tumor, the shortest distance between the tumor and the mediastinum, the shortest distance between the tumor and the hilum, and the diameters of the largest mediastinal or hilar lymph nodes were measured from the thoracic computed tomography (CT) taken at the time of the diagnosis. The relationship between these values and lymph node metastasis was statistically evaluated.

Results: Upon consideration of thoracic CT measurements, lymph node metastasis was found to have a statistically significant relationship with tumors with a large diameter $(>55 \mathrm{~mm})(p<0.001)$, tumors close to the mediastinum $(<7 \mathrm{~mm})$ $(p=0.003)$, and tumors close to the hilum $(<60 \mathrm{~mm})(p=0.045)$. The evaluation of the distinctiveness of markers in diagnosis through ROC analysis showed AUC of $0.70(p<0.001)$ for the largest tumor diameter, and the risk of lymph node metastasis was higher for lesions above $55 \mathrm{~mm}$.

Conclusion: In thorax CT, Large tumor size, tumor close to mediastinum, tumor close to hilum, large lymph node, and high SUV value of lymph node in PET-CT are associated with increased chances of metastasis.
\end{abstract}

Key Words: Lung cancer, Staging, Lymph node, Metastasis.

How to cite this article: Kuzucuoglu M, Gokyer A, Kula O, Yekdes AC, Sunal BS, Karamustafaoglu YA, Yoruk Y, Cicin I. Relationship between the size and location of the mass and hilar and mediastinal lymph node metastasis In early and locally advanced non-small cell lung cancer. J Coll Physicians Surg Pak 2020; 30(2):172-176.

\section{INTRODUCTION}

Lung cancer is a leading cause of cancer-related deaths today. As the most common type, non-small cell lung cancers (NSCLCs) constitute $80-85 \%$ of lung cancers. Surgery is still the most effective treatment for NSCLC. To make a surgical decision, first a good staging is necessary. ${ }^{1-3}$

Correspondence to: Dr.Mustafa Kuzucuoglu, Department of Thoracic Surgery, Faculty of Medicine, Balikesir University, Cagis Kampusu Balikesir, Turkey

E-mail:mustafakuzucuoglu@hotmail.com

Received: September 25, 2019; Revised: January 19, 2020;

Accepted: January 22, 2020
The tumor, lymph node and metastasis (TNM) staging system, developed by Denoix in 1946, was adapted to lung cancer in 1968 by the Union for International Cancer Control (UICC) and in 1973 by the American Joint Committee on Cancer (AJCC). Since 1986, for lung cancer, TNM staging system has been used under the title of International Lung Cancer Staging System. Today, the 8th edition of lung cancer TNM staging system, released in 2017, is being used.2,4,5

Mediastinal lymph node staging is one of the most crucial factors that determine the chance of surgical treatment and prognosis. Therefore, mediastinal node staging in the evaluation of NSCLC must be done very carefully. Invasive or non-invasive methods are applied 
to identify whether there is mediastinal lymph node involvement. $1,6,7$

In this study, the aim was to determine whether there is a relationship between the size and location of the mass and lymph node metastasis.

\section{METHODOLOGY}

The records of the patients who were followed up for non-small cell lung cancer by the Medical Oncology Clinic of Trakya University between November 2013 and November 2018, were retrospectively reviewed. Patients with distant organ metastasis (M1) and distant lymph node metastasis (N3), a previous history of malignancy, synchronous or metachronous tumors, and those for whom required data could not be obtained, were excluded.

The 112 patients included in the study were first evaluated in terms of age, gender, tumor histology and tumor location. The diameter of the tumor, the shortest distance between the tumor and the mediastinum, the shortest distance between the tumor and the hilum, and the diameters of the largest mediastinal or hilar lymph nodes were measured from the contrast thorax computed tomography (CT) of the patients taken at the time of the diagnosis. While the diameter of the tumor and its distance to the mediastinum were measured in the parenchyma window at thorax CT, the shortest distance between the tumor and the hilum was measured in the coronal section of the parenchyma window. The largest mediastinal or hilar lymph node was measured in transverse section and mediastinal window.

Whether the patients had mediastinal or hilar lymph node metastasis was evaluated according to the pathology reports of the postoperatively excised lymph nodes for the patients who underwent surgery; and the pathology reports of lymph node biopsies taken in the procedure for the patients who underwent biopsy through mediastinoscopy, endobronchial ultrasound (EBUS) or endoscopic ultrasound (EUS). In patients who have not undergone any invasive procedures, mediastinal and hilar lymph nodes were evaluated according to positron emission tomography (PET) results. Lymph nodes, which were greater than $1-\mathrm{cm}$ in $\mathrm{CT}$, had higher than 2.5 SUV in PET, evaluated as metastasis in PET report and later confirmed to have metastasis in the oncology council were accepted as having lymph node metastasis. In our study, those without lymph node involvement were classified as having no lymph node metastasis and those with hilar or medastinal lymph node involvement were classified as having lymph node metastasis.

The obtained data were checked for normal distribution with the Shapiro-Wilk test. Independent-samples t-test and Mann-Whitney U-test were used for group comparisons. While the relationships between categorical variables were investigated by Fisher's exact test, the relationships between quantitative variables were identified by Spearman's correlation coefficient. Distinctiveness of markers was evaluated through ROC analysis. Cut-off points for markers were determined with Youden index. The markers were combined using logistic regression. The level of significance for all analyses was set as 0.05 . For statistical analysis, TURCOSA (Turcosa Analytics Ltd Co, Turkey, www.turcosa.com.tr) statistical software was used.

\section{RESULTS}

Of the 112 patients inducted in this study, 105 were males and 7 were females, at the mean age of 63.49 years. Although there was no significant correlation between age and lymph node metastasis, lymph node metastasis was found to be statistically higher in men, but due to the little number of women included in the study, the result was not considered very reliable $(p=0.043)$. The histopathological diagnoses were squamous cell carcinoma $(n=73)$, adenocarcinoma $(n=33)$, adenosquamoz cell carcinoma $(n=4)$ and large cell carcinoma $(n=2)$, but no significant difference was found between tumor histology and lymph node metastasis $(p=0.303)$.

Upon consideration of thorax CT measurements, lymph node metastasis was found to have a statistically significant relationship with tumors with a large diameter $(p<0.001)$, tumors close to the mediastinum $(p=0.003)$, and tumors close to the hilum $(p=0.045$, Table I).

The analysis of the obtained data with Spearman's correlation coefficient revealed a moderate, negative and statistically significant correlation between the markers of the largest tumor diameter and the distance between the tumor and the mediastinum $(r=-0.53$, $\mathrm{p}<0.001$ ), and a moderate, positive and statistically significant correlation between the variables of the distance between the tumor and the mediastinum and the distance between the tumor and the hilum $(r=0.60$, $p<0.001)$. There was a weak, negative and statistically significant correlation between the variables of the largest tumor diameter and the distance between the tumor and the hilum $(r=-0.21, p=0.029)$.

The evaluation of the distinctiveness of markers in diagnosis through ROC analysis has shown that AUC is

Table I: Thoracic CT measurements and lymph node metastasis correlation.

\begin{tabular}{|c|c|c|c|}
\hline \multirow[t]{2}{*}{ Variable } & \multicolumn{2}{|c|}{ Metastasis } & \multirow[t]{2}{*}{$p$-value } \\
\hline & $\begin{array}{c}\text { None } \\
\text { Median } \\
\text { (25th-75 } 5^{\text {th }} \text { percentile) }\end{array}$ & $\begin{array}{c}\text { Yes } \\
\text { Median } \\
\left(25^{\text {th }}-75^{\text {th }} \text { percentile }\right)\end{array}$ & \\
\hline $\begin{array}{l}\text { Largest tumor diameter } \\
\text { in CT }(\mathrm{mm})\end{array}$ & $40(26.25-52)$ & $61.5(37-81.25)$ & $<0.001$ \\
\hline $\begin{array}{l}\text { Shortest distance between } \\
\text { the tumor and the } \\
\text { mediastinum (mm) }\end{array}$ & $5(0-25.5)$ & $0(0-52.25)$ & 0.003 \\
\hline $\begin{array}{l}\text { Distance between the } \\
\text { tumor and the hilum (mm) }\end{array}$ & $62(36-79)$ & $50(33-63)$ & 0.045 \\
\hline
\end{tabular}


$0.70(p<0.001)$ for the largest tumor diameter, and the risk of lymph node metastasis is higher for lesions above $55 \mathrm{~mm}$. For this cut-off point, sensitivity, specificity, positive predictive value and negative predictive value rates were $60.8 \%, 76.3 \%, 83.3 \%$ and $50 \%$, respectively.

For the closest distance of the tumor to the mediastinum, $A \cup C=0.65(p=0.003)$, and tumors at a distance of less than $7 \mathrm{~mm}$ have the risk for metastasis. For this cut-off point, sensitivity, specificity, positive predictive value and negative predictive value rates were $77 \%, 50 \%, 75 \%$ and $52.8 \%$, respectively.

For the distance of the tumor to the hilum, AUC $=0.62$ $(p=0.042)$, and tumors at a distance of less than $60 \mathrm{~mm}$ have the risk for metastasis. For this cut-off point, sensitivity, specificity, positive predictive value and negative predictive value rates were $74 \%, 51.4 \%, 75 \%$ and $50 \%$, respectively.

For the largest lymph node size, AUC $=0.79(p<0.001)$, and for SUV at PET, AUC $=0.91(p<0.001)$. The risk of metastasis is high in lymph nodes over $16 \mathrm{~mm}$ and with SUV above 2.9. For PET value, sensitivity, specificity, positive predictive value and negative predictive value rates were $86.5 \%, 92.1 \%, 95.5 \%$ and $77.8 \%$, respectively (Figure 1).

Although there was a relationship between lymph node metastasis and tumor size, distance from tumor to mediastinum, distance from tumor to hilum, there was no superiority to each other. However, the SUV of lymph node in PET was found to be a significantly sensitive compared to other variables (respectively $p=0.002$, $p<0.001, p<0.001)$.

In the logistic regression model, only tumor size variable was found to be statistically significant on metastasis among tumor size, tumor mediastinal and hilar distance variables $(p=0.034)$. For logistic regression model, sensitivity, specificity, positive predictive value and negative predictive value rates were $82 \%, 60 \%, 80 \%$ and $63 \%$, respectively.

The discriminant performance of markers combined with logistic regression (LR) improved $(A \cup C=0.72)$. However, although the discriminant performance obtained from logistic regression was higher than the singular performance of the variables, this increase was not statistically significant (Table II).

Table II: Logistic regression result of discriminant performance of independent variables.

\begin{tabular}{l|c|c|c|c}
\hline Marker 1 (I) & Marker 2 (J) & $\begin{array}{c}\text { Flexible discriminant } \\
\text { analysis (FDA) (I) }\end{array}$ & $\begin{array}{c}\mathrm{p} \text { value } \\
(\text { corrected })\end{array}$ \\
\hline Largest tumor diameter in CT (mm) & Logistic regression & 0.70 & 0.72 & 0.49 \\
\hline $\begin{array}{l}\text { Shortest distance between the tumor } \\
\text { and the mediastinum (mm) }\end{array}$ & Logistic regression & 0.66 & 0.72 & 0.09 \\
\hline $\begin{array}{l}\text { Distance between the tumor and } \\
\text { the hilum (mm) }\end{array}$ & Logistic regression & 0.62 & 0.72 & 0.00 \\
\hline
\end{tabular}

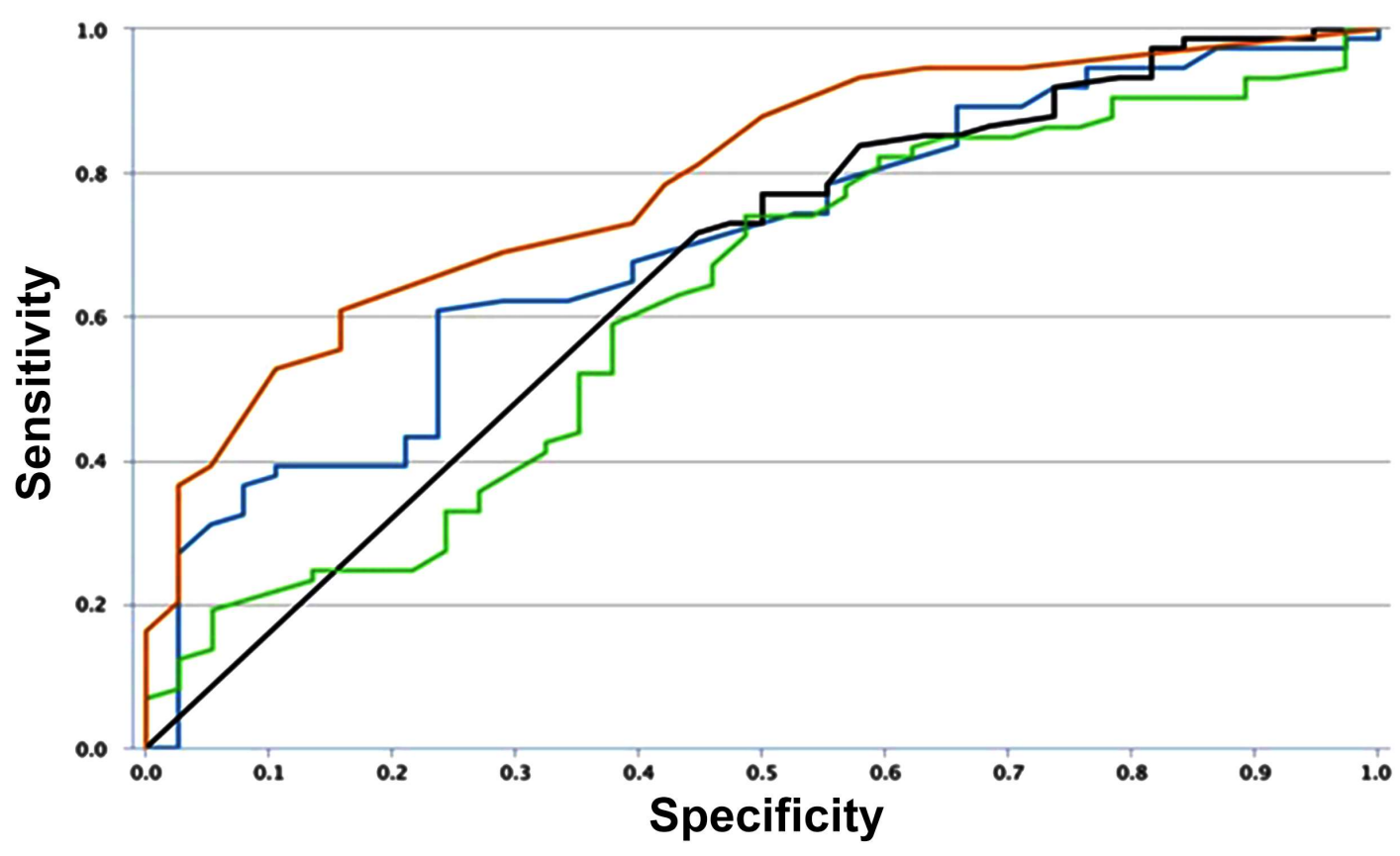

-- The largest diameter of tumor in CT -- Tumor closed to the mediastinum

-- Tumor closed to the hilum -- The largest diameter of lymph node in CT

Figure 1: Sensitivity and specificity of evaluated markers on lymph node metastasis. 


\section{DISCUSSION}

The World Health Organization reported that lung cancer, which is the most common cause of cancerrelated deaths, accounted for $12.9 \%$ of all cancers with 1.8 million new diagnoses in 2012 , resulting in $19.4 \%$ of cancer-related deaths. 5,8

The eighth edition of the lung cancer TNM staging system was created using the data of 77,156 patients out of 94,708 diagnosed with lung cancer between 1999 and 2010; and included in the IASLC database consisting of 5 continents, 16 countries and 35 databases. 4,5 The most significant changes in the new staging system were in the $\mathrm{T}$ and $\mathrm{M}$ classification. In the $\mathrm{N}$ classification. Though nodal stations and zone definitions are described in the $7^{\text {th }}$ edition of lung cancer, TNM staging system are still used without any changes. However, the number of pathological lymph nodes and metastatic lymph node location were shown to be effective in determining the prognosis. Although not included in the new staging, it was suggested that $\mathrm{N} 1$ (ipsilateral peribronchial or hilar lymph node metastasis) classification be divided into subgroups of $\mathrm{N} 1 \mathrm{a}$ and $\mathrm{N} 1 \mathrm{~b}$ for single station $\mathrm{N} 1 \mathrm{~s}$ and multiple station N1s, respectively, and N2 classification (ipsilateral mediastinal lymph node metastasis) into subgroups of N2a1, N2a2 and N2b for single station N2s without N1 metastasis, single station N2s with N1 involvement and those with multiple N2 involvement, respectively. Considering the proposed subgroups, 5-year survival rates in patients with resection were found to be $59 \%$ in $\mathrm{N} 1 \mathrm{a}, 50 \%$ in $\mathrm{N} 1 \mathrm{~b}, 54 \%$ in $\mathrm{N} 2 \mathrm{a} 1,43 \%$ in $\mathrm{N} 2 \mathrm{a} 2$, and $38 \%$ in N2b cases. $4,5,9$

According to the definition of mediastinal zones by IASLC in the seventh edition of lung cancer, TNM staging system, upper mediastinal (1), upper paratracheal (2R and $2 \mathrm{~L}$ ), prevascular or retrotracheal (3), and lower paratracheal (4R and $4 \mathrm{~L}$ ) lymph nodes are located in the superior zone; subaortic (5) and paraaortic (6) lymph nodes are located in the aortic zone; subcarinal (7), paraesophageal (8), and pulmonary ligament (9) lymph nodes are located in the inferior zone.4,6,10 Various studies have been conducted on the relationship between tumor location and mediastinal lymph node metastasis site. In their study on 4,511 patients, Liang et al. ${ }^{6}$ found lymph node metastasis in 1,784 patients; 626 of them had only N1, 752 both N1 and N2, and 404 only N2 metastasis. The most common metastasis was to the upper zone lymph nodes $(48.7 \%)$ in the right upper lobe tumors, to the upper zone lymph nodes $(49.9 \%)$ in the right middle lobe tumors, and to the lower zone lymph nodes (44.5\%) in the left lower lobe tumors. Metastasis to subcarinal lymph nodes in the right lower lobe and left upper lobe was at the rate of $24.4 \%$ and $41.7 \%$, respectively. In the study of Guo et al. ${ }^{1}$, it was shown that right upper lobe tumors had metastasis to lymph nodes in upper zones, left upper lobe tumors to lymph nodes in the aortic zone, and right middle lobe, right lower lobe and left lower lobe tumors to lymph nodes in subcarinal area.

Preoperative lymph node staging is one of the most important parameters in determining treatment and prognosis in lung cancer. Non-invasive, minimally invasive and invasive methods are used. For peripheral tumors smaller than $3 \mathrm{~cm}$, non-invasive thorax CT, PET and cranial magnetic resonance imaging (MRI) methods are usually sufficient. Direct surgical treatment may be an option for these patients. In contrast, for patients with centrally located lesions larger than $3 \mathrm{~cm}$, with lymph nodes found to be larger than $1 \mathrm{~cm}$ in thorax CT, with lymph node SUV found to be above 2.5 in PET, and with adenocarcinoma masses at a high SUV, mediastinal lymph node sampling with invasive methods is recommended. Mediastinoscopy, which is an invasive method, is still the gold standard for mediastinal lymph node sampling despite the use of minimally invasive methods such as EBUS and EUS.11-15 In recent years, EBUS and EUS are the first methods of choice for sampling mediastinal lymph nodes because they are both minimally invasive and can be applied under sedation. Mediastinoscopy must be performed in patients with negative lymph node according to the minimally invasive method but with suspected lymph node in CT or PET.7, 12,16,17

This study results were consistent with the literature and guidelines. In this study, the size of the tumor was found to be the most important factor increasing the risk of mediastinal lymph node metastasis. The critical value for tumor size was found to be $55 \mathrm{~mm}$. In addition, the central location of the tumor and its proximity to the mediastinum and hilum were also found to increase the risk of metastasis. In our study, lymph node size above $16 \mathrm{~mm}$ in thoracic CT and lymph node SUV above 2.9 in PET were found to be critical values in terms of metastasis risk. Although it was not been evaluated in this study, tumor histology, tumor genetics and other pathophysiologic features of the tumor may also affect the risks in terms of metastasis as well as anatomical factors.

Although the variables in this study are prominent as a risk factor for lymph node metastasis, invasive tissue biopsy is the most accurate method to diagnose lymph node metastasis.

\section{CONCLUSION}

Large tumor size, tumor close to mediastinum, tumor close to hilum, large lymph node and high SUV value of lymph node are the factors that increase the risk of metastasis. Mediastinal staging should be performed especially if surgical treatment is to be performed in patients with large tumor size. In addition, the proximity of the tumor to the mediastinum and hilum should be 
considered in terms of the risk of mediastinal lymph node metastasis. Therefore, these factors should be taken into consideration when designing new staging systems. For this, it would be appropriate to carry out extensive studies using prospective methods with larger and more homogeneous case series.

\section{ETHICAL APPROVAL:}

Clinical Ethical Board of Balikesir University approved this study prior to initiation of the research work.

\section{PATIENTS' CONSENT:}

Informed consents were obtained from the patients to use the data.

\section{CONFLICT OF INTEREST:}

Authors declared no conflict of interest.

\section{AUTHORS' CONTRIBUTION:}

MK, YY, YAK: Had a role in the surgical treatment of the patients included in the study.

AG, ACY, IC: Had a role in the medical treatment of the patients included in the study.

OK, BSS: Performed the radiological measurements of the patients included in the study.

MK, AG, OK: Did the design, documentation and writing of the study.

\section{REFERENCES}

1. Guo D, Ni Y, Lv X, Zhang Z, Ye P. Distribution and prognosis of mediastinal lymph node metastases of non-small cell lung cancer. J Can Res Ther 2016;12:120-5.

2. Kuzucuoglu M, Karamustafaoglu YA, Yoruk Y. Comparison of the effects of the sixth and seventh TNM staging on survival in operable non-small cell lung cancer. Cyprus J Med Sci 2018; 3:59-62.

3. Yilmaz HO, Saygi A, Sariman N, Marasli D, Duzgun Y, Köksal H, et al. Relationship of t-stage and nodal metastases according to the up-to-date clinical tnm staging in lung cancer. Turk Gogus Kalp Dama 2012; 20:101-6.

4. Rami-Porta R, Asamura H, Travis WD, Rusch VW. Lung cancer: Major changes in the american joint committee on cancer eight edition staging manual. CA Cancer J Clin 2017; 67:138-55.

5. Lim W, Ridge CA, Nicholson AG, Mirsadraee S. The 8th lung cancer TNM classification and clinical staging system: Review of the changes and clinical implications. Quant Imaging Med Surg 2018; 8:709-18.
6. Liang RB, Yang J, Zeng TS, Long $\mathrm{H}$, Fu JH, Zhang LJ, et al. Incidence and distribution of lobe-specific mediastinal lymph node metastasis in non-small cell lung cancer: Data from 4511 resected cases. Ann Surg Oncol 2018; 25:3300-7.

7. Sehgal IS, Agarwal R, Dhooria S, Prasad KT, Agarwal AR. Role of EBUS TBNA in staging of lung cancer: A clinician's perspective. J Cyto 2019; 36:61-4.

8. Ferlay J, Soerjomataram I, Dikshit R, Eser S, Mathers C, Rebelo $\mathrm{M}$, et al. Cancer incidence and mortality worldwide: Sources, methods and major patterns in globocan 2012. Int $J$ Cancer 2015; 136:359-86.

9. Asamura H, Chansky K, Crowley J, Goldstraw P, Rusch VW, Mitchell $A$, et al. The IASLC lung cancer staging project: proposals for the revision of the $\mathrm{N}$ descriptors in the forthcoming eighth edition of the tnm classification for lung cancer. J Thorac Oncol 2015; 10:1675-84.

10. Rusch VW, Asamura H, Watanabe H, Giroux DJ, Rami-Porta R, Goldstraw $\mathrm{P}$, et al. The IASLC lung cancer staging project: A proposal for a new international lymph node map in the forthcoming seventh edition of the tnm classification for lung cancer. J Thorac Oncol 2009; 4:568-77.

11. Osarogiagbon RU, Lee YS, Faris NR, Ray MA, Ojeabulu PO, Smeltzer MP. Invasive mediastinal staging for resected nonsmall cell lung cancer in a population-based cohort. $J$ Thorac Cardiovasc Surg 2019; 158:1-10.

12. Postmus PE, Kerr KM, Oudkerk M, Senan S, Waller DA, Vansteenkiste $\mathrm{J}$, et al. Early and locally advanced non-small cell lung cancer (NSCLC): ESMO clinical practice guidelines for diagnosis, treatment and follow-up. Ann Oncol 2017; 28:1-21.

13. Howington JA, Blum MG, Chang AC, Balekian AA, Murthy SC. Treatment of stage I and II non-small cell lung cancer: Diagnosis and management of lung cancer, 3rd ed: American college of chest physicians evidence-based clinical practice guidelines. Chest 2013; 143:278-313.

14. Eberhardt WE, De Ruysscher D, Weder W, Le Pechoux C, De Leyn P. 2nd ESMO consensus conference in lung cancer: Locally advanced stage III non-small cell lung cancer. Ann Oncol 2015; 26:1573-88.

15. Van Schil PE, Berzenji L, Yogeswaran SK, Hendriks JM, Lauwers P. Surgical management of stage IIIA non-small cell lung cancer. Front Oncol 2017; 7:249.

16. Sehgal IS, Dhooria S, Aggarwal AN, Behera D, Agarwal R. Endosonography versus mediastinoscopy in mediastinal staging of lung cancer: Systematic review and meta-analysis. Ann Thorac Surg 2016; 102:1747-55.

17. Dhooria S, Sehgal IS, Gupta N, Aggarwal AN, Behera D, Agarwal R. Diagnostic yield and complications of EBUS-TBNA performed under bronchoscopist directed conscious sedation: Single center experience of 1004 subjects. J Bronchology Interv Pulmonol 2017; 24:7-14. 